\title{
Heterodox Economics and Theories of Interactive Agency
}

\author{
Mary V. Wrenn
}

\section{Introduction}

Agency is power - the power to act and the power to choose, the power to imagine, and the power to understand, engage, and manipulate the surrounding biological and social environment. Mainstream economics defines agency in terms of methodological individualism and the individual agent by an optimizing, rational economic man. Agency within the mainstream framework is endowed without discretion to all individuals who independently choose to act based on the weight of 'objective' costs and benefits (Davis 2003; Lavoie 2006). One of the justifications for this simplified depiction of the acting individual is that such behavior is observable in the animal world; indeed 'optimization' may be found at the microscopic level (Hodgson 2004). The explanation of behavior in a Petri dish, however, does not provide a satisfactory or meaningful explanation in the crucible of the real world, with intelligent, creative, and socially situated human beings—at least not to heterodox economists.

The argument set forth here is that heterodox economics is distinguished from mainstream economics by the way in which it conceptualizes and deploys individual agency and consequently, interactive agency. The procedure is straightforward. In the first section, the theory of the individual in heterodox economics is discussed by outlining the conceptualization and internal evolution of the economic agent and her agency, and how that theoretical construct fits 
within the research programs of three heterodox schools of thought: original institutional economics (OIE), Marxian economics, and Post Keynesianism. The second section explores the ways in which these three heterodox schools theorize that an individual's agency changes in response to external forces, both structural sources and mechanisms of mediation between structure and the individual. The third section builds upon the discussion laid out in the previous two sections by detailing the concept of interactive agency, again exploring the similarities and differences between the three heterodox schools. The final section concludes that the similarities which unite these heterodox schools offer a much more complex, nuanced, and ultimately more useful theory of interactive agency and that such complementarity need not require a sacrifice of diversity or pluralism more broadly.

\section{Heterodox theories of the individual}

To the heterodox economist, agency cannot be captured or analyzed by a simple, onedimensional rendering of the individual as is presented by mainstream economics. Agency must instead be examined by its own internal development and responses to external forces; agency must be described not only in terms of how much an individual possesses, but also in terms of how it came to be and how it evolves. The individual, economic agent has antecedents and consequences that give shape to her perceptions of the world and form the individual's mental models. The individual is a totality of her mental models, including models that not only shape perception but that also influence the choice of relevant models to select, apply, filter, and interpret data. An individual's agency is the product of her mental models; in other words, the 
individual's mental models directly influence the degree of agency the individual is able to exercise in the decision-making process.

All individuals engage and exercise agency during their decision making processes; agency and its underlying mental models constitute the mechanism of discretion, and agency is the impetus of action (Smith 2010). The thought process involved in decision making and action can therefore only be understood in terms of the individual's agency and mental models (Pratten 1993). Indeed, agency is crucial in decision theory. Decision theory itself is not only useful in terms of noting what choices individuals make in which context, but in understanding the processes of how individuals choose. A well-developed decision theoretical framework containing a dynamic and interactive interpretation of the individual is thus imperative in understanding the individual and, by extension, in the construction of socially operational, productive, and relevant economic policy (Simon 1978; Lee 2010).

Two sorts of costs emerge when policy makers in government (as well as operationmanagement policy makers within firms) ignore individual behavior and the fundamental importance of agency in constructing efficacious policy. The first is fairly transparent, and simply entails ignoring the basic constitution of the individual in terms of motivation and norms, and thereby essentially missing the objective mark in terms of creating instrumental policy. The second involves the undermining of initially situated norms through the introduction of policy, which is able to reach its intent but does so in a manner that reconstitutes the individual by reshaping her priorities or incentives. Policy maneuvers might reach the desired effect, but do so by stripping away norms already in place, and are inefficient in cost terms. Both 'costs' might emerge in government policy directives meant to direct incentives. For instance, assuming that unemployed individuals are 'lazy' and structuring policy to tighten restrictions on unemployment 
benefits makes presumptions about the incentives internal to the individual. As well, such policy directives may change the structure of norms. Attempting to direct incentives when there is a gap in demand for employment could create a culture among the unemployed, instituting new norms and destroying the very incentive such policy intends to direct (Hargreaves Heap 2001). In this instance, ignoring agency and ignoring the fundamental ontological make-up of individuals may not only lead to inefficacious policy making but dangerous neglect as well.

The OIE maintains a long-standing tradition of rebellion against the methodological individualism of conventional economics. Indeed, the clear goal of Thorstein Veblen was to develop a theory of agency to replace the unsatisfactory theory of the optimizing rational economic man — the "hedonistic ... lightening calculator"—of neoclassical economics (Veblen 1898b: 389). In the development of an alternative theory of agency, the OIE of the early twentieth century placed primacy on the development of a more complete ontology of the individual, paying close attention to the cultural mechanisms, which shaped and channeled the individual's mental models.

For the OIE, the individual is born with certain instincts that have evolved since the emergence of human beings, such as the capacity for language. Humans must have an innate sense of how to communicate in order to physically manipulate the body—lips, tongue, vocal cords, lungs - to produce sound. Once a human is able to communicate, interaction with the surrounding structural context, including inter-subjective relationships with other individuals, builds up the range of language, including dialect and culturally specific rhetoric (Hodgson 2004). The incorporation of instincts into the theory of the individual does not, however, imply universality of ontology or static conceptions of behavior. Evolution may work to change instinct through natural selection: workmanship naturally evolved as an instinctual trait as evidenced by 
the very survival of the human race (Hodgson 2004). Instinct, habit, and patterns of behavior form the building blocks of the individual's mental models.

Marxian thought addresses agency very specifically in terms of the agent-structure relationship under the capitalist rubric, as Marx's historical materialism insists that a single element or individual cannot be studied apart from the totality in which it is situated. Indeed, much of the work in Marxian thought has focused on the individual as part of a collective set within the more general context of society. The insistence of Marxian scholars to examine structural forces is born of this philosophy; that it is impossible to understand the totality from the perspective of the individual as the individual is a product of the totality. The individual is not autonomous but neither is she completely structurally determined.

Individuals are born with base human instincts for survival and in meeting the fundamental physiological needs for survival the individual must manipulate the surrounding environment. This manipulation, set within a community of individuals, becomes organized into a productive process, the development of which is determined by the materials and tools at the disposal of the individuals, and which results in the creation of a social structure that is subject to its own evolutional inertia and to the further manipulation of individuals. Individuals, however, do not remain unaffected by the changing means of survival and production:

[Men] begin to distinguish themselves from animals as soon as they begin to produce their means of subsistence, a step which is conditioned by their physical organization. By producing their means of subsistence, men are indirectly producing their actual material life ... The nature of individuals thus depends on the material conditions determining their production. (Marx \& Engels 1995: 42) 
The individual thus transforms nature into an object for use through the application of labor. The individual is also transformed by the very act of creating that object and its newly created use; what was once imagined becomes a necessity, and further imagination results in the individual again manipulating the surrounding environment to adapt to these newly formed mental models (Gould 1978). "Hunger is hunger, but the hunger gratified by cooked meat eaten with a knife and fork is different from a hunger from that which bolts down raw meat with the aid of hand, nail and tooth" (Marx \& Engels 1995: 132).

Despite, or perhaps because of the diversity within Post Keynesian thought, the concept of agency from a distinctly Post Keynesian perspective is "an area of work that is still in development" (McKenna \& Zannoni 2012: 1). An examination of some of the core concepts which inform the Post Keynesian theory of the individual, however, provides insight into the direction and development of the unfolding progress on this school's conceptualization of agency. The Post Keynesian treatment of uncertainty provides the most obvious and welldeveloped entry point.

Post Keynesians challenge the idea that individuals can foresee the future and rationally understand the consequences of enumerated future events in order to develop a 'well-behaved' preference ordering. It is clear that Post Keynesian fundamental uncertainty is different from the uncertainty found in mainstream economics, for fundamental uncertainty is not based on known and stable probability distributions. Uncertainty takes the form of fundamental uncertainty, which is essentially non-ergodic and reflects the temporally non-syncopated nature of institutional and individual evolution (Dunn 2001; Lavoie 2006). By contrast, risk in mainstream economics relies on epistemological distinctions to account for heterogeneity in individuals. 
Greater access to information in the mainstream framework allows for Bayesian updating of subjective probabilities thereby allowing the individual to approach objective risk through a learning process (Hodgson 1998; Rosser 2001). The theory of fundamental uncertainty is characterized by ontologically non-determined and diverse individuals with heterogeneous mental models. Variations in the ontological and epistemological nature of individuals open the door to innumerable and unforeseeable—-fundamentally unknowable—future possibilities (Dunn 2001; Lavoie 2006).

\section{Structure and mechanisms of mediation}

Mental models and agency are informed but not determined by the surrounding structural context. Structure broadly defined consists of enduring patterns of social relations (Barone 1998). The individual is situated within a historically specific structural context. While sustained, structure is not permanent nor inherently stable (Pratten 1993). Socially and temporally resilient structures may become institutionalized and as such represent "deeply layered," dynamic social complexes (Giddens 1979: 64-65). Institutions therefore differ from structure by virtue of establishment within society and greater ability to influence agency (what Hodgson (2002) refers to as 'reconstitutive downward causation'). The key to the semantic difference is simply that institutions, as a subset of structure, wield greater influence and more directly 'reconstitute' the mental models of agents (Hodgson 2002). For the sake of semantic simplicity, and in order to expose causation rather than obscure focus by differentiating in terms of depth of causation, the remainder of this chapter refers to structures and institutions synonymously. 
Structure, which manifests via the persistent, often tacit, contextual relations within and through which individuals act, partially shapes the individual's agency through various social mechanisms such as power relations, resource allocation, and both formal and informal constraints and obligations. The influence, however, of structure and institutions on agency consists of much more than a mere constraining mechanism (Wrenn 2015). Legal infrastructure, norms and customs of behavior may all act as constraints but those norms and customs which instead change the mental model of the agent, so that she chooses behavior based on preferences not fear of retribution or promise of reward, has changed (i.e., reconstituted) her agency as well. Preferences, therefore, may be changed endogenously as a result of structural pressures. Furthermore, the institutionalization of enduring structures may occur either in objective reality, or as interpretively and subjectively represented in the individual's mental models (Hodgson 2004). As such, the broadly acknowledged systematic guidelines or norms of institutions are incorporated selectively into the mental models of agents and represent mechanisms by which changes in mental models and agency might be mediated.

According to the OIE's theoretical framework, humans at their base have instinctual drives but the working out of these instincts, the behavior through and in which these instincts present themselves, is determined by the cultural milieu to which the individual has been exposed (Hamilton 1953). Habits, which are initiated and reinforced by the structural complex, thus work to modify and develop previously inherited instinctual behavior (Veblen 1898a). This is not to say that the OIE denies or reduces the internal development of agency of the individual or to suggest that 'magical' social forces act to form the individual's mental models, but rather to emphasize that structure changes an individual's mental models, thus changing the very personality, the fundamental essence, of the individual (Hodgson 2004). 
Habits and instincts are part of the cognitive framework, in other words, part of an individual's mental models and are at least partially informed by institutions and structure. Habits, routines, competency base, and skills are not static, but evolve with the changing structure and the changing individual (Davis 2003). Causation, however, does not run one-way from structure through habit to change instincts and behavior in a unidirectional fashion. Indeed, behavioral patterns are the combined result, in subjectively determined portions, of genetic composition, habituation, inertia, enculturation, path dependence, and cumulative causation. Habituation is a stabilizing and creative force in terms of institutional formation and evolution, as well as stabilized and channeled into change by the surrounding structural context (Hodgson 1998).

Institutions and more broadly, structure, are more than just a backdrop; more than just the scaffolding on which to hang human action or a foundation off which to build. Institutions, according to the OIE, are structures, which develop organically, shaping the mental models of individuals and in turn are shaped by humans in all their fallibility. Likewise, individuals carry forward mental models inherited and shaped from past patterns of behavior but are capable of creativity and innovation (Mayhew 2001).

The concept of identity plays a key role in the ontological description of the individual in Marxian theory. In opposition to the highly individualized and self-determined ideologies that buttress the mechanisms of capitalism, Marxian thought focuses on the structural forces that shape the identity of the individual. Class is a social construct yet constitutes the core of identity; class is the lens through which the individual sees herself, the world, and her place in it. Individuals inherit social and class roles and are structurally conditioned from birth to occupy their proper roles through the socialization process and the enculturation of conformity (Barone 
1998). The individual does not exist apart from her class identity and the horizontal relationships therein, and agency is therefore defined at the level of class. Class membership defines, informs, embodies, and is the locus of agency (Parenti 1994; Davis 2003).

Marxian scholars, such as Ebert (2005), stress that a 'productive' concept of agency should be framed in terms of class structure and avoid the secondary structural forces of identity politics that coincide with lifestyle and demographic distinctions, such as race, religion, and gender. This is not to deny structural influences on agency outside of class structure, but rather to see secondary structure in terms and as the result of a historically class-based society: “'Difference' is acquired in identity politics by essentially culturalizing the social divisions of labor" (Ebert 2005: 37-38). As such, agency conceived outside of class identity veils the origins of social structure that evolved as a result of class divisions. Class structure is phenomenon; the secondary structure of identity politics is epiphenomenon. To not place class at the center of inquiry is to deny the driving force behind agency and secondary structure (Bowles \& Gintis 1986; Ebert 2005).

Secondary structure as driven by class structure works to shape identity. Lifestyle and demographics as part of the secondary structure create cross-class or 'fractured identities.' Culture, family, and education constitute the central structures in the socialization process and the means by which social and class roles are rationalized as either inherent or meritocratic (Barone 1998: 16-17). According to Ebert (2005), however, identity politics represents a means by which the managerial class might distinguish itself from the working class without resorting to class distinctions and thereby threatening the existing social order. Focusing on secondary structurally determined identity thus obscures and perpetuates the socially structured inequality of class-based society. 
Structure created by productive relations in turn creates and shapes the remaining structural forms, such as intersubjective relationships and identity. The roles that individuals play, the opportunities presented to them, the perceptions they hold of the world - their mental models - are conscripted by social structure (Pratten 1993). Exploitation of the working class could not persist without an underlying social structure, which shapes the mental models of individuals and makes the relations of production palatable and without which the irrationality of the system might be exposed, leaving it vulnerable to resistance, sabotage, or revolution. Moreover, the persistence of social and ultimately class structures, Barone (1998) argues, cannot be understood in any meaningful way without understanding and studying the culture which perpetuates it. Marxian scholars, such as Gramsci ([1948] 1995), argue that structures outside of class influence individual self-perception, preferences, and which norms would be internalized (Hodgson 2004): "Our capacity to think and act on the world is dependent on other people who are themselves both subjects and objects of history" (Gramsci [1948] 1995: 660). Objective structures and institutions require mental models to sustain both the collective level of socially shared mental models and the individual level to rationalize and sustain (Barone 1998).

The Post Keynesians also recognize the role of the collective (although not necessarily defined in terms of class, as in Marxian economics) in the shaping of an individual's mental models and consequently her agency. In contrast to the strict rationality of mainstream economics, individuals within the Post Keynesian framework at times are driven to action by what Keynes referred to as 'animal spirits' when confronted with uncertainty. As such, individuals rely upon their mental models—described as 'gut instinct'—or act in response to emotional impulses. Individuals might also make intersubjective comparisons, rely on intuition, adopt behavior that conforms to commonly—held beliefs, or get swept up in mob mentalities as 
coping mechanisms and as decision—making guides under uncertainty. Such decision-making devices also serve the purpose of allowing individuals to deflect blame for 'bad' decisions. Under these non-routinized scenarios, uncertainty is fundamentally non-quantifiable and hence, essentially non-ergodic (Rosser 2001).

In non-crucial or routine decisions individuals often rely on conventions to make decisions (Rosser 2001). Conventions inform mental models by acting as heuristic devices, helping to imbue data with meaning as well as form the foundation of social interaction — all of which allow individuals to make decisions under uncertainty. The construction and evolution of mental models is determined in part by the surrounding structural milieu and intersubjective relationships. Likewise, the formation and evolution of institutions will differ according to the mental models of the proximate individuals (McKenna \& Zannoni 2012).

\section{Theories of interactive agency}

Recognition of the ability of structure to change and influence an individual's mental model should not be stretched to the point of determinism. Agency depicted through the socially embedded conceptualization of the individual is not true agency if the individual is not imbued with the power to influence the surrounding structure in a truly interactive fashion. Furthermore, that individual must possess the power of self-reference while recognizing, regardless of accuracy, social influences and her power to act and react to them (Davis 2003). While methodological individualism ignores structural influence on agency, methodological collectivism (or methodological holism) casts the individual as the passive recipient of structural information and pressure (Tauheed 2013). In order to avoid the reductionism of methodological 
individualism and the overly socialized individual of methodological collectivism— - to reject the grandiose delusion of being puppet-masters but also to resist the supine conclusion that [individuals] are mere marionettes" (Archer 1995: 65)—care must be taken to link agency and structure as opposed to subsuming one into the other. Ontologically speaking, agent and structure must be analyzed as separate social strata.

In order not to subsume an agent into structure or structure into an agent, the interdependence of agent and structure must be acknowledged while also recognizing the simultaneous independence of each — the autonomous and internal forces—-that propel agent and structure down their respective evolutionary paths (Tauheed 2013). Structures and agency exist independently and evolve in non-syncopated historical time. The only meaningful way to examine the interplay between agent and structure without submitting one to the evolutional force of the other is to examine the relationship between the two over time (Archer 1995). Thus, structure and agency are approached as simultaneously sensitive to the workings of one another while also consisting, and evolving independently, of independent inertia (Lawson 1997). These theories of interactive agency allow for mutual causation between institutions and agent and simultaneously recognize the interdependence and independence of agent and institutions (Davis 2003). Such respect for the dichotomous forces, which inform the development of agent and structure leads not only to understanding each more clearly but also serves as an important consideration in the development of economic policy. Structural economic policy changes that do not consider or anticipate the interaction between a structural shift and the effected individuals are not likely to succeed. One needs only to turn to the application of shock therapy in Eastern Europe for a striking example of such failure, where political and economic institutions were transformed quickly from centralized planned economies to market economies, 
leaving individuals confused being unaccustomed to these new institutions (see, Taylor 2006; Taylor \& Wrenn 2003).

The interaction between agency and structure provides heterodox economists with a richer, fuller ontological description and explanation of the diverse range of human behavior than that of the calculative individual in mainstream economics. Mainstream economics makes $a$ priori assumptions about the composition and constitution — the ontology — of the individual and therefore her agency, by assuming uniformity in the antecedent, historical context and imagined consequences across all individuals, in effect homogenizing the process by which information is perceived.

Mainstream economics furthermore attempts to differentiate between individuals on epistemological grounds via models, which incorporate imperfect knowledge in an effort to address the diversity between economic agents. To recognize ontological differences between individuals is to recognize the full diversity of mental models that individuals hold and the contextual framework within which those mental models evolved and continue to evolve. Likewise, to respect ontological diversity means to remove wildly independent selfdetermination and appreciate the variation in individual agency. The interactive agency framework, which simultaneously recognizes the interdependence and independence of agent and structure is "so general to accommodate a variety of more specific theories" (Davis 2003: 127-128). This is evident in the examination of the theories of interactive agency for OIE, Marxian economics, and Post Keynesianism.

Interactive agency is a defining theory in the project of the OIE. Individuals inform the composition and functioning of institutions and structure directly and through their intersubjective relationships with one another, and institutions inform the composition and 
functioning of an individual's mental models by reinforcing habits and informing the individual's cognitive process. As such, institutions and individuals maintain their independence — they are not ontologically equivalent—while simultaneously being interdependent (Hodgson 1998).

As a matter of practicality, structure is more enduring and longer-lived, especially once institutionalized, than agent or agency. As a result, the future expectations of the individual are at least partially informed by the current and expected future environment through structural influence on understanding, cognition, and cultural norms. Knowledge as such is embodied not only in the individual but within structure and represents communally held (mostly tacit) knowledge. The individual learns — and adapts her mental models_-from the communal stock of knowledge shared through intersubjective relations, from the structural repository of knowledge and from her own experience (Hodgson 2004).

Hodgson (2004) argues that in his development of the concept of interactive agency, Veblen recognized the mutual dependence between agent and structure as well as the irreducibility of one into the other. By recognizing that agent and structure are also independent entities, the internal integrity of both is acknowledged as well as the temporally asymmetric evolution of each — the antecedents and consequents. Agent and structure evolve partially due to mutual though non-equivalent influence and partially due to internal, independent inertia. Agent and structure are thus mutually causative but not mutually constitutive (Hodgson 2004). The OIE acknowledges the ontological differences in individuals and their mental models as well as the organic evolution of institutions, and, moreover, recognizes the interdependence and independence of each. Agent and structure are both creators and created; are independent and interdependent; mutually causative but not mutually constitutive-in other words, interactive. 
Regardless of the debate within Marxian thought as to whether structure outside of class should be studied in terms of conditioning agency, it is apparent that the relationship between agency and structure is the centerpiece of the Marxian theory of the individual. The collective identity formulation of agency is clearly important in Marxian economics but is not at odds with interactive agency and the internal evolution of the individual. Indeed, the collective is considered a structure and the shared intentions of the collective's members are influenced by the constituency of the collective, thereby allowing for agent-structure interaction within the collective as well as in the more general social structure framework. There is no contradiction between the two: the collective conceptualization of Marxian economics simply adds another layer to the agency-structure relationship (Davis 2003).

Social totality thus consists of three levels: the macro level of institutions; the meso level of collective groups; and, the micro level of the individual. The agency-structure relationship functions through all three levels (Barone 1998). Within the social totality, institutionalized structure and the labor process transform individuals and social groups who, in turn, singly and collectively transform the social structure and totality. Agency and structure evolve according to non-syncopated, independent timetables, yet are simultaneously subject to the pressures and influences of the other's evolutionary path. The interdependence between agency and structure is thus tightly interwoven: agency and structure are interdependent yet maintain their own internal logic and temporally distinct evolutionary progressions (Gould 1978). Agents are not passive recipients of structure — agency and identity are the driving forces behind structural reproduction (whether secondary or primary), persistence, and hysteresis (Barone 1998).

Marx and Marxian scholars possess a heightened sensitivity to social injustice. Social injustice does not exist in ideologies, which emphasize self-determination and wildly 
independent agency. Such ideologies serve to justify existing power structures and sustain the mechanisms of what Marxian scholars perceive to be a dehumanizing system of production (Parenti 1994). Marxian thought emphasizes the relationship between structure and agency in order to address the systemic social injustice inherent in the capitalist system. But Marx and Marxian thought also recognize and respect the individual and the individual's ability to manipulate the surrounding structural environment. The over-socialized or overly structured depiction of the individual and agency, listing too heavily towards methodological collectivism does not accurately characterize the Marxian treatment of the individual. Indeed, Marx himself was writing against the highly individualized writings of the classical economists, and about a system he found noxious and ultimately debilitating in terms of the human spirit and creative impulse (O'Boyle 2013). Marx, however, recognized the essential and intrinsic agency of the individual, the possibilities imbued in the courses of action chosen by the individual, and warned against reifying society and the social structures therein. The individual was not stripped of her agency: agency was cast in light of the structural constraints imposed by the relations of production. Marx viewed the agent-structure relationship as both independent and interdependent (Gould 1978).

Individuals have always built on themselves, but naturally on themselves within their historical conditions and relationships, not on the 'pure' individual in the sense of the ideologists. But ... there appears a division within the life of each individual, insofar as it is personal and insofar as it is determined by some branch of labour and the conditions pertaining to it ... We do not mean it to be understood from this that ... [individuals] 
cease to be persons; but their personality is conditioned and determined by quite definite class relationships. (Marx \& Engels 1995: 83-84)

Regardless of the means of subjugation or dominance, Marx always maintains that the agent remains an agent, never becoming solely an object nor to be understood only in terms of intersubjective relationships (Gould 1978). Indeed, for Marx and in the current Marxian tradition, the agent-structure relationship is interactive-influence runs both ways. To the Marxian economist, however, the social structure of inequality endemic to capitalism and the resulting unnecessary misery imposed on the majority of humankind with its humiliating and crippling effect on the psyche of the individual is of primary focus and concern.

The Cartesian conception of the purely intellectually constructed mental model found in the mainstream's rational economic man is deliberately avoided under the Post Keynesian rubric. The social structure, more than acting as a constraint on choice, partly informs the agent's belief system, while choices made by individuals, in turn, inform the social structure. The individual does however maintain internal integrity and autonomy—-structure is not deterministic and individuals are still capable of free will. Indeed, both structure and agent maintain independence while remaining interactive. The Post Keynesian conceptualization of agency therefore eschews both methodological individualism and methodological collectivism in favor of interactive agency whereby the individual agent makes choices within a cultural context and the choices influence the very social structure wherein the original choice was. Such dynamism need not indicate social instability. The stability of any social structure, or in larger review social system, is insured over the long-run by the very influence of social structure on its constituents; in other 
words, by conventions, rules and norms. Stability does not intimate, however, ergodicity (Todorova 2005; McKenna \& Zannoni 2012).

Although — until relatively recently_largely implicit, Post Keynesian thought addresses and frames agency in interactive terms with "dynamic interaction between agent and structure" (McKenna \& Zannoni 2012: 2). Through fundamental uncertainty and by refuting rational expectations and ergodic uncertainty, however, Post Keynesians have consistently underscored the evolution of mental models within a structural context and the interactive communication and affectation between agent and structure. Moreover, as Post Keynesianism evolves, it is clear that a more well-defined conceptualization of interactive agency continues to coalesce. Lee (2010), in building on the work of Alfred Eichner, explicitly employs interactive agency in order to construct a heterodox macro-micro theory of value. In Lee's (2010) theory interactive agency acts as the critical linchpin which connects individuals and the wider social structure of accumulation and production.

\section{Closing remarks}

Through the discussion of mental models, structure, agency, and their respective evolutions, the three heterodox schools examined herein are able to provide ontological detail about the individual that addresses the range of human behavior and reaches beyond epistemological constraints and maximizing motivations. The three heterodox schools conceptualize the individual and explore the interaction between agent and structure from different theoretical frameworks. Their theoretical constructions of the economic individual are congruous and their constructions of the interactive agency are theoretically compatible. Theories of interactive 
agency are necessary but not sufficient for heterodox economic thought. What distinguishes heterodox economic thought is the constant, temporally asymmetric, back-and-forth affectation between agent and structure, which augments and shapes, but does not entirely determine the nature, composition, and evolutionary paths of each. Complementary theoretical threads running through the frameworks of each of these three schools of heterodox economic thought include elements of non-ergodic and subjective uncertainty, ontological (as opposed to strictly epistemological) distinctions between individuals, temporally non-syncopated evolution of individuals and institutions, and the interdependence and independence of agent and structurein other words, interactive agency.

The OIE and Marxian scholars maintain the strongest and most developed conceptualization of the individual and interactive agency, perhaps because the respective progenitors of each tradition recognized the incumbency in avoiding the self-determined individualism of their historically respective orthodoxies: Marx and classical political economics, Veblen and neoclassical economics. Marx specifically aimed to warn of the debilitating and dehumanizing effects of the structure of the capitalist mode of production on the agency and identity of the individual leading ultimately to her alienation. Likewise, Veblen sought to replace the neoclassical reductivist image of the individual and call attention to the sway of market power and emulative psychosis impinged on the mental models and agency of individuals through consumer-driven society. While within Post Keynesianism, the conceptualization of agency is still an evolving theoretical construct, Post Keynesian thinkers undoubtedly incorporate agency through fundamental uncertainty and the construction of the Post Keynesian macro-micro model of value thereby demonstrating ontological differentiations between individuals as well as interactivity between structure and agent. 
The purpose of this chapter has not been to suggest that these diverse heterodox schools should consolidate or homogenize the economic individual and the discretion and power she is able to exercise in the decision-making process. Such an attempt would run counter to the idea of pluralism embodied in the prefix 'hetero.' Rather, the purpose of this chapter is to suggest that theories of interactive agency present a defining characteristic of heterodox economics and a common base from which heterodox economists might develop not just a critique of mainstream's 'isolated, definitive human datum' but also open the door to a more pluralist economics discipline and greater collegial cross-school discourse. Such a widening of the discipline to a pluralism of thought perhaps will construct more socially-relevant thought and innovation, which might then provide socially-relevant measures of reform.

Heterodox economics may have a more promising future than most imagine. If the elements of an alternative conception of the individual described here coalesce around an increasingly resonant set of concerns regarding individual life in today's socially complex world, the better intuitions that heterodox economists have about institutions and social structures could place them in a position to speak with greater authority about society's concern over the increasing vulnerability of individuals. (Davis 2003: 191)

While some may object to either too broad a spectrum of possibilities as provided by pluralism and others to the dangers in what might be considered consolidating or homogenizing economic thought, the assurance offered by genuine scientific inquiry in economics should satisfy both. Common ground does not suggest common outcomes or common goals. Common, or at the least contributory, ground does however provide a base from which to start economic 
inquiry and integration as well as democratic policy changes. In as much, scientific inquiry and the democratic process are parallel in quest and process: the objective of both is not to simply reach consensus but instead to provide a process by which inquiry and reasoned discourse create an economics that is a self-correcting social science focused on the resolution of social anxieties charged with the task of social reform (Tilman 1987).

\section{References}

Archer, M.S. 1995. Realist Social Theory: The Morphogenetic Approach. Cambridge: Cambridge University Press.

Barone, C. 1998. 'Political economy of classism: towards a more integrated multilevel view.' Review of Radical Political Economics, 30 (2): 1-30.

Bowles, S \& Gintis, H. 1986. Democracy and Capitalism: Property, Community, and the Contradictions of Modern Social Thought. New York: Basic Books.

Davis, J.B. 2003. The Theory of the Individual in Economics: Identity and Value. London: Routledge.

Dunn, S.P. 2001. 'Bounded rationality is not fundamental uncertainty: a Post Keynesian perspective.' Journal of Post Keynesian Economics, 23 (4): 567-587.

Ebert, T.L. 2005. 'Rematerializing feminism.' Science and Society, 69 (1): 33-55.

Giddens, A. 1979. Central Problems in Social Theory: Action, Structure and Contradiction in Social Analysis. Berkeley, CA: University of California Press. 
Gould, C.C. 1978. Marx's Social Ontology: Individuality and Community in Marx's Theory of Social Reality. Cambridge, MA: MIT Press.

Gramsci, A. [1948] 1995. Antonio Gramsci: Further Selections from the Prison Notebooks, edited by D. Boothman. New York: New York University Press.

Hamilton, D.B. 1953. Newtonian Classicism and Darwinian Institutionalism: A Study of Change in Economic Theory. Albuquerque, NM: The University of New Mexico Press.

Hargreaves Heap, S.P. 2001. 'Expressive rationality: is self-worth just another kind of preference,' in: U. Maki (ed.), The Economic World View: Studies in the Ontology of Economics. Cambridge: Cambridge University Press, 98-113.

Hodgson, G.M. 1998. 'The approach of institutional economics.' Journal of Economic Literature, 36 (1): 166-192.

Hodgson, G.M. 2002. 'Reconstitutive downward causation: social structure and the development of individual agency,' in: E. Fullbrook (ed.), Intersubjectivity in Economics: Agents and Structures. London: Routledge, 159-180.

Hodgson, G.M. 2004. The Evolution of Institutional Economics: Agency, Structure, and Darwinism in American Institutionalism. London: Routledge.

Lavoie, M. 2006. 'Do heterodox theories have anything in common? A post-Keynesian point of view.' European Journal of Economics and Economic Policies: Intervention, 3 (1): 87112.

Lawson, T. 1997. Economics and Reality. London: Routledge.

Lee, F.S. 2010. 'Alfred Eichner's missing "complete model”: a heterodox micro-macro model of a monetary production economy,' in: M. Lavoie, L.-P. Rochon, \& M. Seccareccia (eds.), 
Money and Macrodynamics: Alfred Eichner and Post-Keynesian Economics. London: Routledge, 22-42.

Marx, K. \& Engels, F. 1995. The German Ideology. New York: International Publishers.

Mayhew, A. 2001. 'Human agency, cumulative causation, and the state.' Journal of Economic Issues, 35 (2): 239-250.

McKenna, E.J. \& Zannoni, D.C. 2012. 'Agency,' in: J.E. King (ed.), The Elgar Companion to Post Keynesian Economics, $2^{\text {nd }}$ edn. Cheltenham, UK: Edward Elgar, 1-5.

O'Boyle, B. 2013. 'Reproducing the social structure: a Marxist critique of Anthony Giddens's structuration methodology.' Cambridge Journal of Economics, 37 (5): 1019-1033.

Parenti, M. 1994. Land of Idols: Political Mythology in America. New York: St. Martin's Press.

Pratten, S. 1993. 'Structure, agency and Marx's analysis of the labour process.' Review of Political Economy, 5 (4): 403-426.

Rosser, J.B. 2001. 'Alternative Keynesian and Post Keynesian perspectives on uncertainty and expectations.' Journal of Post Keynesian Economics, 23 (4): 545-566.

Simon, H.A. 1978. 'Rational decision-making in business organizations: Nobel memorial lecture,' in: A. Lindbeck (ed.), Economic Sciences. Singapore: World Scientific Publishing, 343-371.

Smith, C. 2010. What is a Person? Rethinking Humanity, Social Life, and the Moral Good from the Person Up. Chicago: The University of Chicago Press.

Tauheed, L.F. 2013. "A critical institutionalist reconciliation of "contradictory" institutionalist institutions: institutions and social provisioning.' Journal of Economic Issues, 47 (4): 827-853. 
Taylor, L.J. 2006. The role of informal institutions in the transition: how households in Krasnodar, Russia are coping with change. Ph.D Dissertation. Colorado State University Taylor, L.J. \& Wrenn, M.V. 2003. 'Forging new relationships: social capital in the transition.' Forum for Social Economics, 33 (1): 1-11.

Tilman, R. 1987. 'The neoinstrumental theory of democracy.' Journal of Economic Issues, 21 (3): 1379-1401.

Todorova, Z. 2005. 'Habits of thought, agency, and transformation: An institutional approach to feminist ecological economics.' Feminist Economics, 11 (3): 126-132.

Veblen, T. 1898a. 'The instinct of workmanship and the irksomeness of labor.' The American Journal of Sociology, 4 (2): 187-201.

Veblen, T. 1898b. 'Why is economics not an evolutionary science?' The Quarterly Journal of Economics, 12 (4): 373-397.

Wrenn, M.V. 2007. 'Searching for common ground: interactive agency in heterodox economics.' European Journal of Economics and Economic Policies: Intervention, 4 (2): 247-269.

Wrenn, M.V. 2015. 'Agency and neoliberalism.' Cambridge Journal of Economics, 39 (5): 1231-1243. 